\title{
Drug Transport to Brain with Targeted Liposomes
}

\author{
Anita Schnyder* and Jörg Huwyler ${ }^{\dagger}$ \\ Department of Research and Division of Clinical Pharmacology, University Hospital Basel, CH-4031 Basel, Switzerland; \\ and F. Hoffmann-LaRoche Ltd., Pharmaceuticals Division, CH-4070 Basel, Switzerland
}

\begin{abstract}
Summary: Antibody-conjugated liposomes or immunoliposomes are particulate drug carriers that can be used to direct encapsulated drug molecules to diseased tissues or organs. The present review discusses examples of successful applications of this technology to achieve drug transport across the blood-brain barrier. In addition, information will be provided on practical aspects such as phospholipid compositions of liposomes, anti-
\end{abstract}

body coupling technologies, large-scale production of liposomes, and obstacles related to drug loading of the carrier. Prospects of future uses of immunoliposome-based drug delivery systems such as gene therapy of the brain and clinical trials are discussed. Key Words: Brain targeting, blood-brain barrier, immunoliposomes, liposomes.

\section{STRUCTURE OF IMMUNOLIPOSOMES}

\section{Liposomes and steric stabilization}

Liposomes can be described as vesicles in which an aqueous inner volume is entirely enclosed by a phospholipid membrane bilayer. In pharmaceutical sciences, liposomes have been used traditionally as formulation ingredients to assist in formulation of poorly soluble therapeutic agents for oral or parenteral administration. The antibiotic amphotericin B is an example of a marketed drug that makes use of this formulation principle for intravenous infusion. ${ }^{1}$ The pharmacokinetics of conventional liposomes, i.e., liposomes that consist of naturally occurring phospholipids and cholesterol, is characterized by a very high systemic plasma clearance. Such vesicles are rapidly removed from the circulation after intravenous administration by macrophages of the reticuloendothelial system, namely the liver, the spleen, and the bone marrow. ${ }^{2}$ The liposome half-life in the circulation can be prolonged considerably by incorporation of gangliosides (such as monosialoganglioside $\mathrm{GM}_{1}$ derived from bovine brain ${ }^{3}$ ) or polyethylene glycol (PEG) derivatized lipids within the phospholipid bilayer of conventional liposomes. ${ }^{4-6}$ Conventional liposomes coated with the inert and biocompatible polymer PEG are often referred to as sterically stabilized liposomes. The PEG

Address correspondence and reprint requests to PD Dr. Jörg Huwyler, F. Hoffmann-LaRoche Ltd., Pharmaceuticals Division, PRBD-E, Building 70-310a, CH-4070 Basel, Switzerland. E-mail: joerg. huwyler@roche.com. coating is believed to prevent binding of opsonins from physiological fluids such as plasma, which in turn avoids the recognition by phagocytotic cells. ${ }^{7}$ PEG phospholipids are safe and can be prepared synthetically at high purity and in large quantities, which has led to their acceptance for clinical applications. Animal and human studies ${ }^{8}$ have demonstrated pronounced differences with respect to pharmacokinetic parameters between conventional and sterically stabilized PEG liposomes: in humans, pegylation of liposomes resulted in a 50-fold decrease in plasma volume of distribution to a value similar to the plasma volume (from 200 to 4.5 liters), a 200 -fold decrease in systemic plasma clearance from 22 to 0.1 1/hour and a nearly 100-fold increase in area under the time-concentration curve. ${ }^{9}$ The apparent terminal halflife of PEG liposomes reached up to $90 \mathrm{~h}$ in human. ${ }^{8}$ The extended circulation half-life of sterically stabilized liposomes in combination with an increased permeability of tumor vasculature results in passive accumulation of PEG liposomes in solid end-stage tumors. ${ }^{10}$ This principle of passive targeting to tumor tissue has been applied to commercial formulations of doxorubicin used for the chemotherapy of malignant Kaposi's sarcoma or breast cancer. ${ }^{11}$

\section{Immunoliposomes}

Long-circulating PEG liposomes have a minimal affinity to cells in vitro and nondiseased tissues in vivo and provide therefore a biologically inert and safe platform for the design of drug delivery systems. The organ and 
tissue distribution of the sterically stabilized liposomes can be modulated by conjugation of an appropriate targeting vector. Examples of such vectors include proteins, peptides, and small molecules such as the vitamin folate, which was used to target folate-receptor overexpressing tumor cells. ${ }^{12,13}$ With respect to brain drug delivery vectors, modified proteins or antibodies are used that undergo absorptive-mediated or receptor-mediated transcytosis through the blood-brain barrier. Examples of brain targeting vectors include cationized albumin, the OX26 monoclonal antibody to the rat transferrin receptor, or monoclonal antibodies to the insulin receptor. ${ }^{14,15}$

Different types of coupling strategies have been developed to attach proteins to phospholipids or pegylated phospholipids while preserving their biological activity. Covalent coupling to phospholipids can be achieved using, for example, amino-reactive homobifunctional cross-linkers. ${ }^{16,17}$ Water-soluble carbodiimides can be used to catalyze the formation of an amide linkage between amines of the phospholipid headgroups and carboxyl moieties of proteins. ${ }^{18}$ Thiolated $\mathrm{F}\left(\mathrm{ab}^{\prime}\right)_{2}$ fragments and maleimidated phosphatidylethanolamine ${ }^{19,20}$ can be linked by disulfide bonds. A major drawback of the direct coupling of proteins to the liposome surface is the observation that the PEG chains may have a strong shielding effect that prevents the interaction between the bound receptor ligand and its receptor. ${ }^{21}$ In a liposome agglutination assay, as little as $0.72 \mathrm{~mol} \%$ of $\mathrm{PEG}^{5000}$. phosphatidylethanolamine (PEG of molecular mass 5000 Da) completely abolished the interaction between phospholipid-bound biotin and streptavidin. ${ }^{22}$ The shielding effect did also reduce target binding in vivo of immunoliposomes by up to $50 \%$ and was highly dependent on PEG chain length. ${ }^{23}$ The effect of pegylation was less pronounced or not present at PEG molecular masses of 2000 or $750 \mathrm{Da}$.

As opposed to direct coupling to the phospholipid headgroup region on the liposome surface, ligands can be attached at the terminus of the PEG chains (FIG. 1, A and C). Thus, PEG is used as a spacer that results in a better accessibility and flexibility of the vector. ${ }^{24-26}$ By this strategy, the immunoliposome target binding efficiency in vitro ${ }^{27}$ as well as in vivo ${ }^{25}$ increases by a factor of two to three. The PEG interactions associated with different coupling strategies and the dimensions of an immunoliposome are visualized in Fig 1. The minimal size of an unilamellar liposome is determined by the maximal tolerated proximity of the phospholipid headgroups imposed by the curvature of the inner leaflet. This minimal size is $\sim 80 \mathrm{~nm}$ for liposomes that have as main constituents lecithin-analogs and cholesterol. ${ }^{28}$ Approximately $30 \%$ of the inner volume of a $80 \mathrm{~nm}$ liposome are occupied by the phospholipid bilayer that has a thickness of 4-5 nm. The hydrophilic PEG ${ }^{2000}$ corona has a thickness of $5 \mathrm{~nm}$ as shown by electron microscopy. ${ }^{27}$ By the same

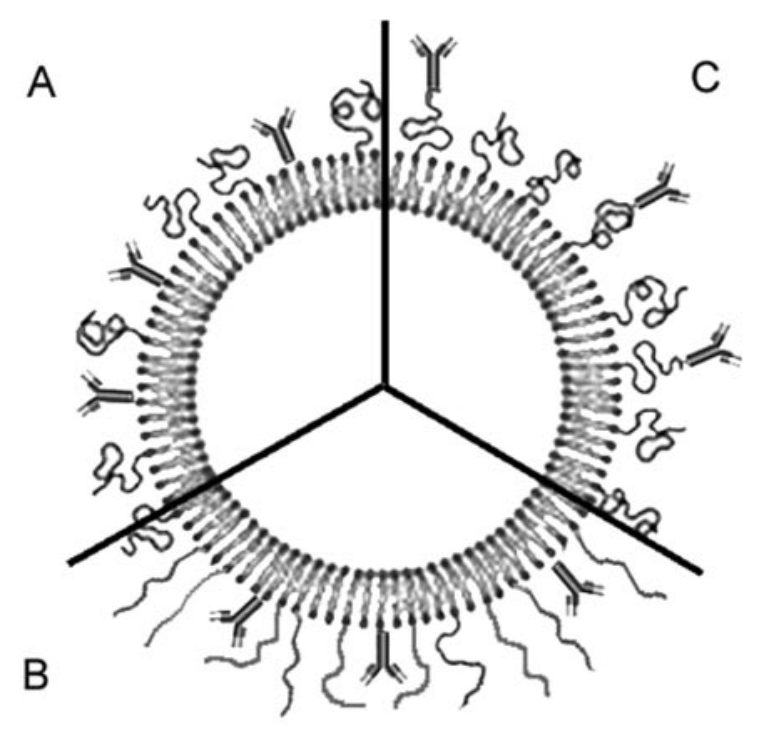

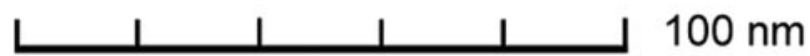

FIG. 1. Schematic representation of pegylated immunoliposomes where the antibody is bound directly to the liposome surface (section A) or to the distal tip of the PEG chains (C). The relative sizes are representative for a $80 \mathrm{~nm}$ liposome decorated with $\mathrm{PEG}^{2000}$ (PEG of molecular mass $2000 \mathrm{Da}$ ). When attached to the liposome surface, steric hindrance between the PEG chains in their coiled (A) as well as extended (B) conformation and the antigen-recognition site of the antibody can be expected.

technique, the apparent dimensions of an antibody are determined to be in the range of 10-15 nm. Direct measurement of PEG-tethered ligand-receptor interaction potentials confirms a thickness of $5 \mathrm{~nm}$ for $\mathrm{PEG}^{2000}$ in its coiled state (FIG. 1A) and an overall length of an extended PEG-2000 chain of $15 \mathrm{~nm}^{29}$ (FIG. 1B). These considerations emphasize that a corona of PEG-2000 blocks substantially the access of a surface-bound antibody to its epitope. This steric hindrance will further increase using PEG molecules of higher molecular weights.

Different techniques have been developed for the covalent binding of proteins to pegylated phospholipids by cleavable (e.g., disulfide) or metabolically stable (e.g., thioether, amide, or imide) linker strategies..$^{24,25,30,31}$ In general, the choice of a specific coupling procedure is guided by practical considerations such as coupling efficiency and the need to retain the antigenicity of the coupled antibody despite the introduced chemical modifications. The target recognition by the coupled antibody may also depend on the orientation (i.e., random or defined) of the antibody or a $\mathrm{Fab}^{\prime}$ on the liposome surface and the resulting accessibility of the antibody binding sites to their respective epitopes. ${ }^{32}$

Covalent binding protocols rely in general on chemically reactive PEG-phospholipid derivatives that are part of the phospholipid/cholesterol mix used for the synthesis of the PEG liposomes. The liposomes are loaded with drug, reduced in size and purified before the actual cou- 
pling procedure is performed by addition of the vector. The latter may undergo a chemical modification (i.e., chemical introduction of functional groups) before use. The disadvantage of such protocols is the observation that the efficiency of the coupling procedure is very difficult to control due to competing (hydrolytic) reactions.

In attempts to develop more reproducible and flexible coupling procedures that may be used for the large-scale production of immunoliposomes, alternative methods have been introduced recently. ${ }^{33-35}$

Iden et al. ${ }^{33}$ developed a postinsertion technique that involves the coupling of ligands to the terminus of PEGlipid derivatives in a micellar phase. At a later time point, the ligand-coupled PEG-lipids are transferred into the bilayers of preformed liposomes during a simple incubation step $\left(1 \mathrm{~h}\right.$ at $\left.60^{\circ} \mathrm{C}\right)$. The final product is purified by sizeexclusion-chromatography. Therapeutic effect, cytotoxicity and binding of immunoliposomes made by the postinsertion technique was comparable with the ones of immunoliposomes made by a conventional coupling technique. ${ }^{32}$

We have introduced a coupling procedure that makes use of a biotinylated PEG-phospholipid and a streptavidin-conjugated antibody. ${ }^{35}$ Preformed and purified biotin-PEG-liposomes are thereby simply mixed with the streptavidin-conjugated antibody to result immediately in a quantitative coupling. The biotin-streptavidin interaction is among the strongest noncovalent affinities known and is characterized by a dissociation constant of about $1.3 \times 10^{-15} \mathrm{M}$. Excess binding sites on the streptavidin molecule are blocked by free biotin to avoid crosslinking and thus aggregation of the biotinylated immunoliposomes.

\section{Loading of liposomes}

The use of immunoliposomes as drug delivery systems requires adequate techniques for the generation of unilamellar vesicles and for the encapsulation of drugs and macromolecules. With respect to drug loading, several methods have been described. Whereas first attempts relied on passive entrapment methods with a low loading efficiency, more recent methods make use of more efficient strategies such as loading by transmembrane ion gradients (i.e., a $\mathrm{pH}$ or specific salt gradient).

Passive entrapment can be done by hydration of phospholipids and the preparation of liposomes in presence of the molecule of interest followed by purification of the liposomes and their separation from nonincorporated material by gel-filtration chromatography. ${ }^{36}$ Lipophilic or amphiphilic drugs will thereby partition into the lipid bilayer that leads to a quantitative and efficient loading of the liposomes. For water-soluble compounds, which partition into the aqueous phase of the lumen of the liposome, the amount of entrapped drug is directly proportional to the initial drug concentration used in the incubation mix and the total inner volume of the result-

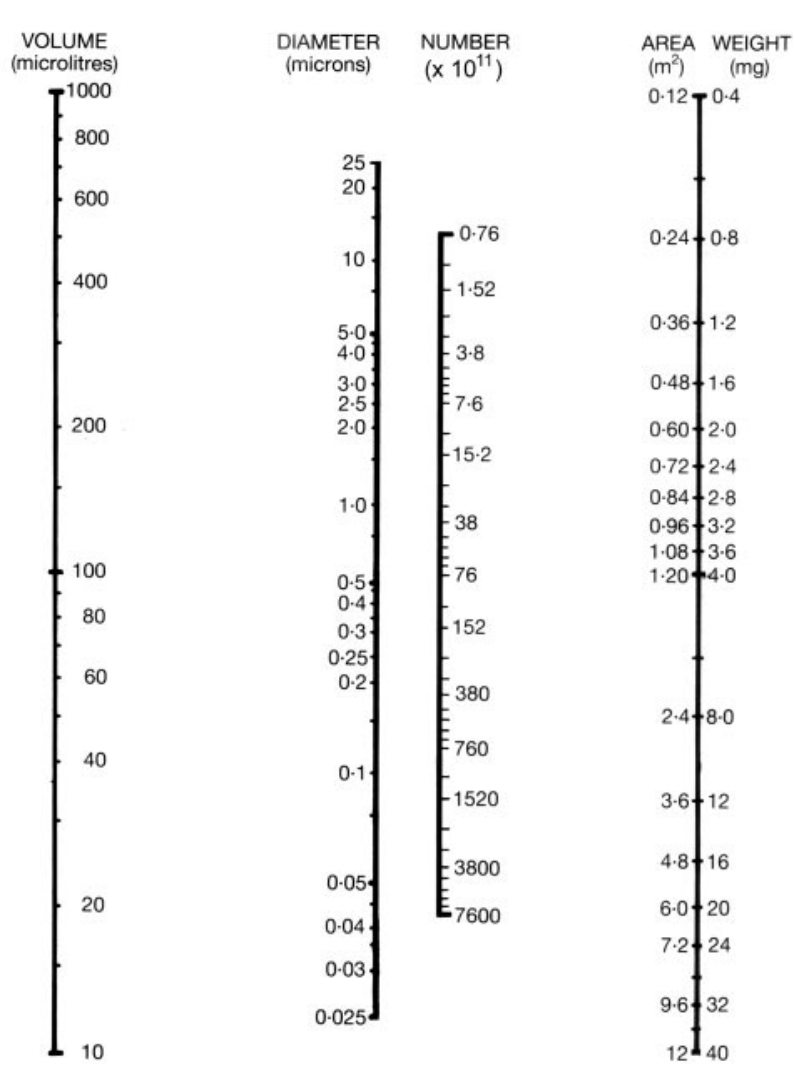

FIG. 2. Nomogram relating theoretical captured volume, diameter, number, area, and lipid weight of unilamellar liposomes. To read the nomogram, connect two known parameters by a straight line and read off the unknown parameter where this line intersects the third scale. The calculation is based on the assumption that the phosphatidyl choline headgroup occupies an area of the membrane bilayer of $42 \AA^{2}$. Note that the smallest possible diameter for an unilamellar liposome is on theoretical grounds $25 \mathrm{~nm}$. Adapted with permission from New. Liposomes: a practical approach. Copyright $\odot$ 1990, Oxford University Press. All rights reserved. ${ }^{28}$

ing liposomes. The latter depends on liposome diameter, and lipid concentration and can be related to these parameters using a nomogram (FIG. 2) ${ }^{28}$ Because the inner volume of liposomes represents a small percentage of the whole liposome suspension only, the efficiency of this method is low and a considerable amount of (expensive) material is not incorporated and therefore lost. This can be illustrated based on theoretical considerations with the help of the nomogram in Figure 2: liposomes with a diameter of $100 \mathrm{~nm}$ that are prepared using $4 \mathrm{mg}$ of lecithin will have an outer surface of $1.2 \mathrm{~m}^{2}$. These $6 \times$ $10^{13}$ liposomes will capture a theoretical volume of as little as $15 \mu \mathrm{l}$. One single 100-nm liposome will be made up of $\sim 150,000$ phospholipid molecules assuming that the phosphatidyl choline headgroup occupies an area of the membrane bilayer of $42 \AA^{2}$.

The loss of hydrophilic biological macromolecules such as proteins, plasmids, and enzymes during the passive loading process can be reduced using highly concentrated liposomal solutions. Solutions of preformed 
liposomes are thereby concentrated by ultrafiltration or partial lyophilization. The molecule of interest is added and incorporated into the liposomes by several freezethaw cycles. The freezing and thawing is used to rupture and re-fuse the liposomes, during which time the solute equilibrates between the inside and outside. This method has been used recently, for example, to incorporate DNA into neutral liposome formulations. ${ }^{37}$ Problems associated with this method may be a poor entrapment stability (i.e., leakage of the encapsulated molecules after dilution and purification of the liposomes) and influences on size and heterogeneity of the preformed liposomes. ${ }^{38}$

The remote (active) loading of drug molecules into preformed liposomes is generally a very efficient loading technique and can result in a sustained incorporation of small molecules. The underlying principle is the use of $\mathrm{pH}$ or ion gradients to create an electrochemical potential across the phospholipid-bilayer of the liposome that in turn leads to active uptake and entrapment of a given drug within the liposome. The gradient is generated by a two-step process: after preparation of liposomes in a buffer of a certain $\mathrm{pH}$ and ion strength, the external medium is exchanged by size exclusion chromatography. ${ }^{12,38,39}$ This method has been applied with success to small, weakly basic molecules such as doxorubicin and vincristine. Under appropriate conditions, they precipitate as a gel within the liposome. ${ }^{38}$ This leads to quantitative uptake with incorporation efficiencies approaching $100 \%$ as well as a stable retention within the liposome. It is important to note that the use of such liposomal formulations greatly enhances the carrying capacity of the coupled vector. For example, $\sim 28,000$ small molecules of daunomycin can be packed within a single 100-nm liposome and can be directed to a target tissue using just a few conjugated antibodies. ${ }^{31}$ Thus, antibody to drug ratios of 1000 are possible using 100-nm immunoliposomes. This value is in sharp contrast to the 1:1 ratios obtained by individual attachment of drugs to a targeting vector. ${ }^{40}$

In general, the choice, the optimization, and the validation of a specific loading technique may be a complex problem depending on the physico-chemical properties of a given drug. To assess suitability of a liposome-based drug delivery system for in vivo use, careful in vitro tests should be performed to evaluate loading efficiency, loading capacity and stability of entrapment upon large dilutions in physiological fluids.

\section{BRAIN TARGETING USING IMMUNOLIPOSOMES}

\section{Pharmacokinetics and tissue distribution}

Long-circulating, sterically stabilized liposomes show minimal interactions with tissues and organs and can be considered to be neutral and inert carriers for encapsu- lated molecules. Their pharmacokinetics and tissue distribution will therefore largely depend on the nature of a coupled targeting vector. First attempts to use liposomes for brain targeting were made using pegylated liposomes conjugated to a murine monoclonal antibody to the rat transferrin receptor, the OX26 monoclonal antibody. ${ }^{31}$

The OX26 monoclonal antibody was shown before to achieve a high degree of brain delivery. After a single intravenous injection, $0.26 \%$ of the injected dose per gram can be found in brain tissue at $60 \mathrm{~min}^{41}$ as a result of both a high blood-brain barrier PS product (i.e., bloodbrain barrier permeability) as well as high plasma AUC of the antibody. Using the internal carotid artery brain perfusion and capillary depletion technique, ${ }^{42}$ it could be shown that the OX26 monoclonal antibody is transported across the blood-brain barrier by receptor-mediated transcytosis. $^{43,44}$ In vivo, brain uptake of the OX26 monoclonal antibody is not inhibited by endogenous transferrin despite the saturation of the BBB transferrin receptor (which has a $\mathrm{K}_{\mathrm{D}}$ of $6 \mathrm{nM}$ ) by the micromolar transferrin concentrations in plasma. ${ }^{45}$ In addition, minimal inhibition of transferrin transport by OX26 was observed as long as the plasma OX26 concentration was less than $10 \mu \mathrm{g} / \mathrm{ml}$, which would not be generated in vivo unless toxic doses of the OX26 mAb were given. These findings suggest that the antibody recognizes a binding site on the transferrin receptor that is distant to the one of the natural ligand transferrin. ${ }^{40}$

Conjugation of the OX26 monoclonal antibody to sterically stabilized liposomes had a profound impact on the pharmacokinetics and tissue distribution of the pegylated liposomes. ${ }^{31,46}$ The systemic plasma clearance of the immunoliposomes did increase by a factor of 5 and was paralleled by a two-fold increase in volume of distribution at steady state. In contrast to pegylated liposomes, the immunoliposomes did accumulate in brain tissue. An average brain delivery of $0.03 \%$ of the injected dose per gram tissue was observed at $60 \mathrm{~min}$ after intravenous injection. Control experiments indicated that brain uptake was mediated by the OX26 monoclonal antibody because exchange of this antibody for an unspecific $\operatorname{IgG}_{2 \mathrm{a}}$ isotype antibody did eliminate the targeting. In addition, tissue levels of OX26 immunoliposomes were reduced by competition with the coinjected unbound OX26 monoclonal antibody. Titration of the amount of bound antibodies revealed in vivo an optimal antibody density of 30 antibodies per $100 \mathrm{~nm}$ liposome. Higher amounts of bound antibodies result in a reduction of the steric stabilization effect of the PEG and therefore to a poor targeting efficiency in vivo (as opposed to the situation in vitro where such saturation effects are not seen $^{36}$ ). Quite interestingly, this optimal number of $\sim 30$ vectors per liposome was also observed in experiments where pulmonary endothelial cells were targeted in vivo using 34A monoclonal antibody conjugated liposomes. ${ }^{25}$ 


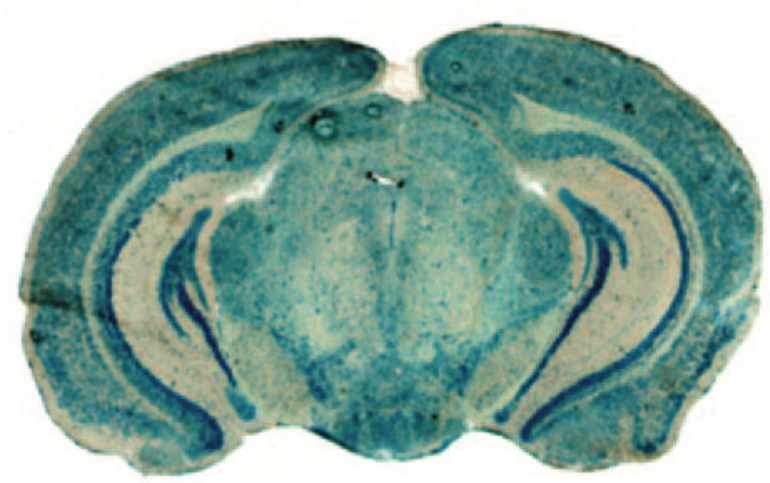

FIG. 3. $\beta$-Galactosidase histochemistry of a section of mouse brain $48 \mathrm{~h}$ after a single intravenous injection of a $\beta$-galactosidase expression plasmid encapsulated within a pegylated immunoliposome. The used targeting vector is the 8D3 monoclonal antibody to the mouse transferrin receptor. The expression of the exogenous gene is under the control of the brain-specific GFAP promoter. Reproduced with permission from Shi et al. Brain-specific expression of an exogenous gene after i.v. administration. Proc Natl Acad Sci USA 98:12754-12759. Copyright ${ }^{\circledR}$ 2001, National Academy of Sciences. All rights reserved. ${ }^{48}$

Several lines of evidence suggest that OX26 immunoliposomes accumulate in brain tissue followed by transport across the blood-brain barrier and deposition within brain parenchyma. First, the brain tissue volume of distribution of intravenously injected OX26 immunoliposomes increases over a 24 -h period of time being indicative of accumulation of OX26 immunoliposomes in brain tissue. ${ }^{31}$ Second, transcytosis of OX26-immunoliposomes across rat brain capillary endothelial cells could be shown using an in vitro model of the blood-brain barrier that is based on immortalized RBE4 rat brain capillary endothelial cells. ${ }^{47}$ Third, the in situ brain perfusion and capillary depletion technique did confirm transcytosis in vivo in the rat: OX26 immunoliposomes were recovered after intravenous infusion within the postvascular compartment of brain parenchyma. A sole association with the apical membrane domain of the brain microvasculature was excluded. ${ }^{47}$ Fourth, intravenous infusion in the rat of OX26 immunoliposomes carrying an expression plasmid encoding $\beta$-galactosidase did result in gene expression throughout the CNS including neurons and was not limited to the brain microvasculature $^{37,48}$ (FIG. 3). In another set of experiment, this nonviral gene delivery using OX26 immunoliposomes was associated with a clear pharmacological effect resulting from reversible normalization of striatal tyrosine hydroxylase expression in a rat model of Parkinsonism. ${ }^{49}$ Taken together, these findings clearly demonstrate transcytosis of OX26 immunoliposomes across the bloodbrain barrier in vitro as well as in vivo.

\section{Targeting of small molecules}

Immunoliposome-based drug delivery systems are of special interest for targeting of molecules that cannot be coupled directly to a transport vector. This can be small drugs that have to achieve micromolar concentrations in a target tissue to have a pharmacological effect. ${ }^{50,51}$ Possible indications are the chemotherapy of neoplastic diseases as liposomal formulations of anthracycline antibiotics are often characterized by quantitative encapsulation and retention in liposomes. ${ }^{52}$ The first clinical application of antibody-conjugated liposomes was a recent phase I trial in oncology. ${ }^{53}$ Doxorubicin encapsulated in PEG immunoliposomes was administered by $1-\mathrm{h}$ infusions every 3 weeks in raising dose levels to 23 patients with metastatic or recurrent stomach cancer. The duration of the treatment period was between 48 and 135 days. The used targeting vector was a $\mathrm{F}\left(\mathrm{ab}^{\prime}\right)_{2}$ fragment of a cancerreactive human monoclonal antibody $(\mathrm{GAH})$, which showed high binding (with a positive ratio of $>90 \%$ ) to cells obtained from cancerous stomach tissues. ${ }^{54}$ The antibody was grafted by a postinsertion method to the surface of PEG liposomes. Stable disease (but no antitumor response) was observed in 10 of 18 evaluable patients with a tolerance similar to Doxil, a doxorubicin formulation based on pegylated liposomes. ${ }^{55}$ This study is an impressive demonstration of the technical feasibility of the clinical application of antibody-conjugated liposomes. However, the pharmacological efficacy of this particular design of immunoliposomes (where the antibody was conjugated to the surface of the liposome and not to the tip of the PEG-5000 chains) remains to be shown.

In addition to therapeutic applications, a possible future use of immunoliposomes might include their use as diagnostic tools to localize, for example, tumor tissue ${ }^{56}$ or amyloid plaques in Alzheimer's disease. ${ }^{57,58}$ Such applications rely on brain delivery of quantitative amounts of contrast agents such as magnetoferritin ${ }^{59}$ or gadolinium. ${ }^{60}$ Recent in vivo studies using a C6 glioma rat brain tumor model indicate that liposomal gadolinium might indeed be used for the visualization of tumor tissue by in vivo magnetic resonance imaging (MRI). ${ }^{61}$ In this study, gadolinium-loaded liposomes were delivered to tumor tissue by convection-enhanced delivery, an invasive technique where drugs are infused under pressure into brain white matter. ${ }^{62}$

\section{Gene targeting}

Controlled gene delivery to the brain is a potential strategy to treat diseases of the CNS. However, direct intracerebral implantation of a therapeutic gene by means of a viral vector, such as adenovirus or herpes simplex virus, provokes an inflammatory response and demyelination in many animals and virtually all humans. ${ }^{63,64}$ The incorporation of DNA in the interior of stealth immunoliposomes would therefore inhibit such immune reactions due to viral antigens and, additionally, 
prevent supercoiled plasmid DNA from degradation by ubiquitous nucleases in vivo.

Complexes between cationic lipids and DNA are often used to transfect cultured cells or tissues. An application of this technology for in vivo gene delivery is problematic because DNA-cationic liposome form micrometerscale aggregates, particularly at lipid to DNA ratios where the overall charge of the complex is neutral. ${ }^{65}$ As a consequence, their pharmacokinetics and tissue distribution is characterized by a very short plasma half-live (e.g., a few minutes in the mouse) and an unspecific accumulation in different organs. ${ }^{66}$ Microautoradiography of tissue samples at $24 \mathrm{~h}$ after injection of cationic lipid-DNA complexes revealed uptake of expressionplasmid DNA in cells of the reticuloendothelial system, i.e., alveolar macrophages, hepatic Kupffer cells, and macrophages of the spleen. DNA uptake per tissue was in this as well as in other studies significantly higher in lung (up to $1^{\prime} 000$ fold) than in liver or spleen. ${ }^{67}$ It is tempting to speculate that the efficient transfection of lung tissue might be a direct consequence of quantitative first-pass filtration of particulate DNA-lipid aggregates in the lung.

An alternative to DNA/cationic liposome complexes is the use of neutral liposome formulations. The DNA is thereby encapsulated within the liposome. The neutral liposome can be pegylated and subsequently coupled to a targeting vector. Such a targeted gene delivery system is characterized by a high stability of the encapsulated DNA under physiological conditions and a prolonged circulation half life in vivo. ${ }^{37,68}$ Several studies have demonstrated that exogenous gene expression in the brain can be achieved using such a gene-delivery system: Shi et al. ${ }^{37,69}$ incorporated an expression plasmid coding for either $\beta$-galactosidase or luciferase in the interior of pegylated OX26-immunoliposomes. In vivo gene expression was shown at 2-6 days after a single intravenous administration (FIG. 3).

The tissue specificity of gene expression in a given target tissue (e.g., the brain) can be further enhanced by the combined use of such a gene targeting technology and tissue-specific gene promoters. In a recent study, ${ }^{48}$ $\beta$-galactosidase exogenous expression plasmids under the control of either the unspecific simian virus 40 (SV40) promoter or by a brain-specific promoter (taken from the $5^{\prime}$ flanking region of the GFAP gene), were incorporated in pegylated immunoliposomes and injected intravenously into mice. The used targeting vector was a monoclonal antibody against the mouse transferrin receptor (8D3 mAb). The expression in mice of the $\beta$-galactosidase gene was restricted to brain tissue in experiments where the $\beta$-galactosidase gene was under the control of the brain-specific GFAP promoter (FIG. 3). In contrast, immunoliposomes loaded with expression plasmids controlled by the unspecific SV40 promoter caused $\beta$-galactosidase expression in all transferrin receptor rich organs, e.g., brain, liver, spleen, and lung.

Several studies indicate that gene expression in brain after immunoliposome-based gene therapy may translate to pharmacological effects in vivo. OX26 immunoliposomes were used to normalize tyrosine hydroxylase activity in an animal model of Parkinson's disease, ${ }^{49}$ which did result in reversal of apomorphine-induced rotation behavior in 6-hydroxydopamine-lesioned rats. In another study, the immunoliposome-mediated gene targeting technology was used for brain delivery of a therapeutic gene in a human brain tumor model consisting of scid mice implanted with intracranial U87 human glial brain tumors. ${ }^{70}$ The expression plasmid did encode a short hairpin RNA directed at a nucleotide sequence within the human epidermal growth factor receptor (EGFR). The used targeting vectors were the murine $83-14 \mathrm{mAb}$ to the human insulin receptor and the rat $8 \mathrm{D} 3 \mathrm{mAb}$ to the mouse transferrin receptor. This intravenous RNA interference gene therapy resulted in silencing of EGFR expression in tumor cells both in vitro as well as in vivo leading to a significant increase in survival time of mice with implanted brain tumors. The pharmacological effect on brain cancer cells in vivo provides evidence that macromolecules such as plasmid DNA can be delivered across consecutive series of biological barriers that included in the discussed gene therapy studies the bloodbrain barrier, the plasma membrane of the target cells within the brain tissue and the nuclear membrane. ${ }^{71}$

\section{PERSPECTIVES}

\section{Multifunctional liposomes and intracellular targeting}

Long-circulating pegylated liposomes can be seen as a starting point for the design of multifunctional drug carrier systems. The properties of such targeted liposomes can be modulated and adopted to different needs by the combination of different types of vectors and enzymes bound to the liposome surface. Previous reports describe the design of immunoenzymosomes, i.e., immunoliposomes bearing enzymes on their surface that catalyze the conversion of prodrugs into active parent compounds. ${ }^{72}$ Vingerhoeds et al. ${ }^{73}$ used a $\beta$-glucuronidase bearing enzymosome drug targeting system, directed against ovarian carcinoma cells by $\mathrm{F}\left(\mathrm{ab}^{\prime}\right)_{2}$ fragments of the mouse monoclonal 323/A3 antibody. This antibody recognizes a surface glycoprotein on a variety of carcinomas. After binding of immunoenzymosomes to the target cells, the prodrug is administered and converted into the active drug in close proximity of the tumor cell. The density of the enzyme is thus increased substantially at the target cell surface using such a liposome-based targeting strategy. This is in particular valuable for tumors with little antigen expression. 
A strategy to enhance intracellular release of liposomal drugs is the use of $\mathrm{pH}$-sensitive liposomes. Such liposomal formulations release their contents spontaneously in an environment with a decreased $\mathrm{pH}$. Liposomes encounter such changes in $\mathrm{pH}$ during the process of receptor mediated endocytosis as the $\mathrm{pH}$ in the endosomal compartment is characterized by a $\mathrm{pH}$ of $\sim 5.5$. $^{74}$ Destabilization of the liposomal membrane can be induced by bound amphiphilic peptides that adopt an $\alpha$-helical conformation in an acidic environment ${ }^{75}$ or the use of mixtures of cationic and ionizable anionic lipids. ${ }^{76}$ Such $\mathrm{pH}$-sensitive liposomes are typically prepared from mixtures of dioleoylphosphatidylethanolamine (DOPE), which adopts a non-bilayer inverted hexagonal $\left(\mathrm{H}_{\mathrm{II}}\right)$ phase in isolation, and a ionizable anionic lipid such as cholesterolhemisuccinate (CHEMS). In its negatively charged form at elevated $\mathrm{pH}$ values, CHEMS stabilizes the DOPE in its bilayer organization. Protonation of the CHEMS at $\mathrm{pH}$ values below its $\mathrm{pK}$ abolishes its stabilizing effect leading to membrane inversion, membrane fusion and the release of entrapped substances into the liposome-surrounding compartment. ${ }^{77}$ This technology can be applied both to conventional liposomes as well as long-circulating, sterically stabilized liposomes. ${ }^{78}$

Liposomes can be decorated with two or even more different peptidomimetic antibodies or targeting fragments to increase liposomal delivery of an incorporated drug or plasmid DNA to both extracellular epitopes as well as intracellular compartments. For example, one vector might be responsible for brain tissue targeting and another for inducing cellular uptake or intracellular transport. This strategy is based on the observation that some antigens may be attractive targets in terms of patterns of expression, yet, they are poor at delivering their cargo (e.g., DNA) to the appropriate cellular (e.g., nuclear) compartment. ${ }^{34}$

Zhang et al. ${ }^{79}$ investigated a delivery system with liposomes coupled to two different antibodies that target the mouse transferrin receptor and the human insulin receptor. Injected into mice implanted with human glial brain tumors, the mouse transferrin receptor enables transport across the tumor vasculature (which is of mouse brain origin), and the insulin receptor causes transport across the plasma membrane and the nuclear membrane of the human brain cancer cell.

In another set of experiments, ${ }^{34}$ liposomes were linked to a first antibody to the transferrin receptor and a second antibody specific for E-selectin. Targeting of the transferrin receptor offers a rapid internalization of the liposomal complex by receptor-mediated endocytosis. Tissue selectivity of the immunoliposomes is thereby enhanced by the antibody against E-Selectin, which exhibits a distinct and endothelial-selective pattern of expression.

\section{Clinical use of immunoliposomes}

Recent phase I clinical trials with immunoliposomes ${ }^{53}$ demonstrate that liposome-based targeting technologies have the potential to find their way from the bench to the bedside. Formulations of pegylated liposomes have been on the market for many years. We have now the technologies at hand (using efficient coupling strategies for vectors such as postinsertion techniques ${ }^{32}$ and biotinstreptavidin coupling strategies ${ }^{35}$ ) to expand the use of such liposomal formulations to the targeted delivery of drugs to organs and tissues. Once produced, liposomal formulations should be applied immediately or within short periods of time to minimize leakage of the liposomal content. As discussed earlier, remote loading techniques are available for selected drugs that are characterized by high loading efficiencies and a stable retention of the transported drug within the liposomal carrier. However, loading of peptides, plasmids and DNA is in general still problematic and expensive due to the low efficiency of entrapment.

Lyophilization may be a possibility to stabilize liposomal formulations and to minimize their storage in a dissolved and diluted state. A formulation kit for doxorubicin composed of lyophilized liposomes was developed recently by Stevens et al. ${ }^{80}$ providing a strategy to expand the shelf-life of liposomal formulations.

With respect to brain targeting of liposomes, the success of this as well as any other physiological and noninvasive brain targeting strategy will depend on the availability of efficient and brain-specific targeting vectors. As of today, there does not exist an ideal brain vector. Such a molecule would have to recognize a target that is expressed exclusively at the brain capillary endothelium, would not compete with endogenous ligands, and would be transported with high efficiency across the blood-brain barrier by receptor-mediated transcytosis. The transferrin receptor, to name a well-characterized example, is expressed in several other organs than the brain. As a consequence, targeting of immunoliposomes coupled to antitransferrin receptor antibodies is not confined solely to the brain. Other organs such as the liver ${ }^{46}$ or skeletal muscle ${ }^{35}$ are recognized as well. It is therefore tempting to speculate that in the future the design of immunoliposomes using alternative brain delivery vectors (such as antibodies directed at the insulin receptor $)^{68,70}$ might allow for higher targeting efficiencies bringing this technology to its full potential.

Acknowledgments: Anita Schnyder is recipient of a studentship from F. Hoffmann-LaRoche Ltd., Basel, Switzerland.

\section{REFERENCES}

1. Gulati M, Bajad S, Singh S, Ferdous AJ, Singh M. Development of liposomal amphotericin B formulation. J Microencapsul 15:137151, 1998. 
2. Frank MM. The reticuloendothelial system and bloodstream clearance. J Lab Clin Med 122:487-488, 1993.

3. Allen TM, Chonn A. Large unilamellar liposomes with low uptake into the reticuloendothelial system. FEBS Lett 223:42-46, 1987.

4. Papahadjopoulos D, Allen TM, Gabizon A, Mayhew E, Matthay K, Huang SK, et al. Sterically stabilized liposomes: improvements in pharmacokinetics and antitumor therapeutic efficacy. Proc Natl Acad Sci USA 88:11460-11464, 1991.

5. Woodle MC, Matthay KK, Newman MS, Hidayat JE, Collins LR, Redemann C, et al. Versatility in lipid compositions showing prolonged circulation with sterically stabilized liposomes. Biochim Biophys Acta 1105:193-200, 1992.

6. Uster PS, Allen TM, Daniel BE, Mendez CJ, Newman MS, Zhu GZ. Insertion of poly(ethylene glycol) derivatized phospholipid into pre-formed liposomes results in prolonged in vivo circulation time. FEBS Lett 386:243-246, 1996.

7. Moghimi SM, Patel HM. Opsonophagocytosis of liposomes by peritoneal macrophages and bone marrow reticuloendothelial cells. Biochim Biophys Acta 1135:269-274, 1992.

8. Gabizon A, Shmeeda H, Barenholz Y. Pharmacokinetics of pegylated liposomal Doxorubicin: review of animal and human studies. Clin Pharmacokinet 42:419-436, 2003.

9. Allen TM. Long-circulating (sterically stabilized) liposomes for targeted drug delivery. Trends Pharmacol Sci 15:215-220, 1994.

10. Gabizon A, Papahadjopoulos D. Liposome formulations with prolonged circulation time in blood and enhanced uptake by tumors. Proc Natl Acad Sci USA 85:6949-6953, 1988.

11. Gabizon AA. Pegylated liposomal doxorubicin: metamorphosis of an old drug into a new form of chemotherapy. Cancer Invest 19:424-436, 2001

12. Goren D, Horowitz AT, Tzemach D, Tarshish M, Zalipsky S, Gabizon A. Nuclear delivery of doxorubicin via folate-targeted liposomes with bypass of multidrug-resistance efflux pump. Clin Cancer Res 6:1949-1957, 2000.

13. Lee RJ, Low PS. Delivery of liposomes into cultured KB cells via folate receptor-mediated endocytosis. J Biol Chem 269:31983204, 1994.

14. Pardridge WM. Brain drug delivery and blood-brain barrier transport. Drug Delivery 1:83-101, 1993.

15. Wu D, Yang J, Pardridge WM. Drug targeting of a peptide radiopharmaceutical through the primate blood-brain barrier in vivo with a monoclonal antibody to the human insulin receptor. J Clin Invest 100:1804-1812, 1997.

16. Torchilin VP, Goldmacher VS, Smirnov VN. Comparative studies on covalent and noncovalent immobilization of protein molecules on the surface of liposomes. Biochem Biophys Res Commun 85: 983-990, 1978 .

17. Hermanson GT. Bioconjugate techniques. San Diego: Academic Press, 1996.

18. Dunnick JK, McDougall IR, Aragon S, Goris ML, Kriss JP. Vesicle interactions with polyamino acids and antibody: in vitro and in vivo studies. J Nucl Med 16:483-487, 1975

19. Martin FJ, Papahadjopoulos D. Irreversible coupling of immunoglobulin fragments to preformed vesicles. An improved method for liposome targeting. J Biol Chem 257:286-288, 1982.

20. Suzuki S, Watanabe S, Masuko T, Hashimoto Y. Preparation of long-circulating immunoliposomes containing adriamycin by a novel method to coat immunoliposomes with poly(ethylene glycol). Biochim Biophys Acta 1245:9-16, 1995.

21. Kaasgaard T, Mouritsen OG, Jorgensen K. Screening effect of PEG on avidin binding to liposome surface receptors. Int J Pharm 214:63-65, 2001

22. Klibanov AL, Maruyama K, Beckerleg AM, Torchilin VP, Huang L. Activity of amphipathic poly(ethylene glycol) 5000 to prolong the circulation time of liposomes depends on the liposome size and is unfavorable for immunoliposome binding to target. Biochim Biophys Acta 1062:142-148, 1991.

23. Mori A, Klibanov AL, Torchilin VP, Huang L. Influence of the steric barrier activity of amphipathic poly(ethyleneglycol) and ganglioside GM1 on the circulation time of liposomes and on the target binding of immunoliposomes in vivo. Febs Lett 284:263266, 1991.
24. Shahinian S, Silvius JR. A novel strategy affords high-yield coupling of antibody Fab' fragments to liposomes. Biochim Biophys Acta 1239:157-167, 1995.

25. Maruyama K, Takizawa T, Yuda T, Kennel SJ, Huang L, Iwatsuru M. Targetability of novel immunoliposomes modified with amphipathic poly(ethylene glycol)s conjugated at their distal terminals to monoclonal antibodies. Biochim Biophys Acta 1234:74-80, 1995.

26. Allen TM, Brandeis E, Hansen CB, Kao GY, Zalipsky S. A new strategy for attachment of antibodies to sterically stabilized liposomes resulting in efficient targeting to cancer cells. Biochim Biophys Acta 1237:99-108, 1995.

27. Bendas G, Krause A, Bakowsky U, Vogel J, Rothe U. Targetability of novel immunoliposomes prepared by a new antibody conjugation technique. Int J Pharm 181:79-93, 1999.

28. New RRC. Liposomes: a practical approach. Oxford, UK: Oxford University Press, 1990.

29. Wong JY, Kuhl TL, Israelachvili JN, Mullah N, Zalipsky S. Direct measurement of a tethered ligand-receptor interaction potential. Science 275:820-822, 1997.

30. Hansen CB, Kao GY, Moase EH, Zalipsky S, Allen TM. Attachment of antibodies to sterically stabilized liposomes: evaluation, comparison and optimization of coupling procedures. Biochim Biophys Acta 1239:133-144, 1995.

31. Huwyler J, Wu D, Pardridge WM. Brain drug delivery of small molecules using immunoliposomes. Proc Natl Acad Sci USA 93: 14164-14169, 1996.

32. Allen TM, Sapra P, Moase E, Moreira J, Iden D. Adventures in targeting. J Liposome Res 12:5-12, 2002.

33. Iden DL, Allen TM. In vitro and in vivo comparison of immunoliposomes made by conventional coupling techniques with those made by a new post-insertion approach. Biochim Biophys Acta 1513:207-216, 2001.

34. Tan PH, Manunta M, Ardjomand N, Xue SA, Larkin DF, Haskard DO, et al. Antibody targeted gene transfer to endothelium. J Gene Med 5:311-323, 2003.

35. Schnyder A, Krahenbuhl S, Torok M, Drewe J, Huwyler J Targeting of skeletal muscle in vitro using biotinylated immunoliposomes. Biochem J 377:61-67, 2004.

36. Torchilin VP, Weissig V. Liposomes. New York: Oxford University Press, 2003.

37. Shi N, Pardridge WM. Noninvasive gene targeting to the brain. Proc Natl Acad Sci USA 97:7567-7572, 2000.

38. Lasic DD, Ceh B, Stuart MCA, Guo L, Frederik PM, Barenholz Y. Transmembrane gradient driven phase transitions within vesicles: lessons for drug delivery. Biochimica et Biophysica Acta 1239: 145-156, 1995.

39. Hwang SH, Maitani Y, Qi XR, Takayama K, Nagai T. Remote loading of diclofenac, insulin and fluorescein isothiocyanate labeled insulin into liposomes by $\mathrm{pH}$ and acetate gradient methods. Int J Pharm 179:85-95, 1999.

40. Pardridge WM. Vector-mediated peptide drug delivery to the brain. Adv Drug Delivery Rev 15:109-146, 1995.

41. Bickel U, Yoshikawa T, Pardridge WM. Delivery of peptides and proteins through the blood-brain barrier. Adv Drug Deliv Rev 10: 205-245, 1993.

42. Triguero D, Buciak J, Pardridge WM. Capillary depletion method for quantification of blood-brain barrier transport of circulating peptides and plasma proteins. J Neurochem 54:1882-1888, 1990.

43. Friden PM, Walus LR, Musso GF, Taylor MA, Malfroy B, Starzyk RM. Anti-transferrin receptor antibody and antibody-drug conjugates cross the blood-brain barrier. Proc Natl Acad Sci USA 88: 4771-4775, 1991

44. Pardridge WM, Buciak JL, Friden PM. Selective transport of an anti-transferrin receptor antibody through the blood-brain barrier. J Pharmacol Exp Ther 259:66-70, 1991.

45. Skarlatos S, Yoshikawa T, Pardridge WM. Transport of $\left[{ }^{125} \mathrm{I}\right]$ transferrin through the rat blood-brain barrier. Brain Res 683:164-171, 1995.

46. Huwyler J, Yang J, Pardridge WM. Receptor mediated delivery of daunomycin using immunoliposomes: pharmacokinetics and tissue distribution in the rat. J Pharmacol Exp Ther 282:1541-1546, 1997.

47. Cerletti A, Drewe J, Fricker G, Eberle AN, Huwyler J Endocytosis 
and transcytosis of an immunoliposome-based brain drug delivery system. J Drug Target 8:435-446, 2000.

48. Shi N, Zhang Y, Zhu C, Boado RJ, Pardridge WM. Brain-specific expression of an exogenous gene after i.v. administration. Proc Natl Acad Sci USA 98:12754-12759, 2001.

49. Zhang Y, Calon F, Zhu C, Boado RJ, Pardridge WM. Intravenous nonviral gene therapy causes normalization of striatal tyrosine hydroxylase and reversal of motor impairment in experimental parkinsonism. Hum Gene Ther 14:1-12, 2003.

50. Wang S, Low PS. Folate-mediated targeting of antineoplastic drugs, imaging agents, and nucleic acids to cancer cells. J Control Release 53:39-48, 1998.

51. Carlsson J, Kullberg EB, Capala J, Sjoberg S, Edwards K, Gedda L. Ligand liposomes and boron neutron capture therapy. $\mathrm{J} \mathrm{Neu}$ rooncol 62:47-59, 2003.

52. Lasic DD. Doxorubicin in sterically stabilized liposomes. Nature 380:561-562, 1996.

53. Matsumura Y, Gotoh M, Muro K, Yamada Y, Shirao K, Shimada $\mathrm{Y}$, et al. Phase I and pharmacokinetic study of MCC-465, a doxorubicin (DXR) encapsulated in PEG immunoliposome, in patients with metastatic stomach cancer. Ann Oncol 15:517-525, 2004.

54. Hosokawa S, Tagawa T, Niki H, Hirakawa Y, Nohga K, Nagaike $\mathrm{K}$. Efficacy of immunoliposomes on cancer models in a cellsurface-antigen-density-dependent manner. Br J Cancer 89:15451551, 2003.

55. Gabizon A, Catane R, Uziely B, Kaufman B, Safra T, Cohen R, et al. Prolonged circulation time and enhanced accumulation in malignant exudates of doxorubicin encapsulated in polyethylene-glycol coated liposomes. Cancer Res 54:987-992, 1994.

56. Mamot C, Nguyen JB, Pourdehnad M, Hadaczek P, Saito R, Bringas JR, et al. Extensive distribution of liposomes in rodent brains and brain tumors following convection-enhanced delivery. $\mathrm{J} \mathrm{Neu}$ rooncol 68:1-9, 2004.

57. Lee HJ, Zhang Y, Zhu C, Duff K, Pardridge WM. Imaging brain amyloid of Alzheimer disease in vivo in transgenic mice with an A $\beta$ peptide radiopharmaceutical. J Cereb Blood Flow Metab 22: 223-231, 2002.

58. Kurihara A, Pardridge WM. A $\beta(1-40)$ peptide radiopharmaceuticals for brain amyloid imaging: (111)In chelation, conjugation to poly(ethylene glycol)-biotin linkers, and autoradiography with Alzheimer's disease brain sections. Bioconjug Chem 11:380-386, 2000.

59. Bulte JW, Douglas T, Mann S, Frankel RB, Moskowitz BM, Brooks RA, et al. Magnetoferritin: characterization of a novel superparamagnetic MR contrast agent. J Magn Reson Imaging 4:497-505, 1994.

60. Arnold DL, Matthews PM. MRI in the diagnosis and management of multiple sclerosis. Neurology 58:S23-S31, 2002.

61. Saito R, Bringas JR, McKnight TR, Wendland MF, Mamot C, Drummond DC, et al. Distribution of liposomes into brain and rat brain tumor models by convection-enhanced delivery monitored with magnetic resonance imaging. Cancer Res 64:2572-2579, 2004.

62. Bobo RH, Laske DW, Akbasak A, Morrison PF, Dedrick RL, Oldfield EH. Convection-enhanced delivery of macromolecules in the brain. Proc Natl Acad Sci USA 91:2076-2080, 1994.

63. Herrlinger U, Kramm CM, Aboody-Guterman KS, Silver JS, Ikeda $\mathrm{K}$, Johnston KM, et al. Pre-existing herpes simplex virus 1 (HSV-1) immunity decreases, but does not abolish, gene transfer to experimental brain tumors by a HSV-1 vector. Gene Ther 5:809$819,1998$.
64. Kajiwara K, Byrnes AP, Ohmoto Y, Charlton HM, Wood MJ, Wood KJ. Humoral immune responses to adenovirus vectors in the brain. J Neuroimmunol 103:8-15, 2000.

65. Radler JO, Koltover I, Salditt T, Safinya CR. Structure of DNAcationic liposome complexes: DNA intercalation in multilamellar membranes in distinct interhelical packing regimes. Science 275: 810-814, 1997.

66. Osaka G, Carey K, Cuthbertson A, Godowski P, Patapoff T, Ryan A, et al. Pharmacokinetics, tissue distribution, and expression efficiency of plasmid [33P]DNA following intravenous administration of DNA/cationic lipid complexes in mice: use of a novel radionuclide approach. J Pharm Sci 85:612-618, 1996.

67. Liu Y, Mounkes LC, Liggitt HD, Brown CS, Solodin I, Heath TD, et al. Factors influencing the efficiency of cationic liposome-mediated intravenous gene delivery. Nat Biotechnol 15:167-173, 1997.

68. Zhang Y, Jeong Lee H, Boado RJ, Pardridge WM. Receptormediated delivery of an antisense gene to human brain cancer cells. J Gene Med 4:183-194, 2002.

69. Shi N, Boado RJ, Pardridge WM. Receptor-mediated gene targeting to tissues in vivo following intravenous administration of pegylated immunoliposomes. Pharm Res 18:1091-1095, 2001.

70. Zhang Y, Zhang YF, Bryant J, Charles A, Boado RJ, Pardridge WM. Intravenous RNA interference gene therapy targeting the human epidermal growth factor receptor prolongs survival in intracranial brain cancer. Clin Cancer Res 10:3667-3677, 2004.

71. Zhang Y, Schlachetzki F, Pardridge WM. Global non-viral gene transfer to the primate brain following intravenous administration. Mol Ther 7:11-18, 2003.

72. Vingerhoeds MH, Haisma HJ, van MM, van, de, Rijt, et al. A new application for liposomes in cancer therapy. Immunoliposomes bearing enzymes (immuno-enzymosomes) for site-specific activation of prodrugs. FEBS Lett 336:485-490, 1993.

73. Vingerhoeds MH, Haisma HJ, Belliot SO, Smit R, Crommelin D, Storm G. Immunoliposomes as enzyme-carriers (immuno-enzymosomes) for antibody-directed enzyme prodrug therapy (adept)optimization of prodrug activating capacity. Pharm Res 13:604610, 1996.

74. Tycko B, DiPaola M, Yamashiro DJ, Fluss S, Maxfield FR. Acidification of endocytic vesicles and the intracellular pathways of ligands and receptors. Ann NY Acad Sci 421:424-433, 1983.

75. Vogel K, Wang S, Lee RJ, Chmielewski J, Low PS. Peptidemediated release of folate-targeted liposome contents from endosomal compartments. J Am Chem Soc 118:1581-1586, 1996.

76. Duezguenes N, Nir S. Mechanisms and kinetics of liposome-cell interactions. Adv Drug Deliv Rev 40:3-18, 1999.

77. Hafez IM, Ansell S, Cullis PR. Tunable pH-sensitive liposomes composed of mixtures of cationic and anionic lipids. Biophys $J$ 79:1438-1446, 2000.

78. Slepushkin VA, Simoes S, Dazin P, Newman MS, Guo LS, Pedroso dLM, et al. Sterically stabilized $\mathrm{pH}$-sensitive liposomes. Intracellular delivery of aqueous contents and prolonged circulation in vivo. J Biol Chem 272:2382-2388, 1997.

79. Zhang Y, Zhu C, Pardridge WM. Antisense gene therapy of brain cancer with an artificial virus gene delivery system. Mol Ther 6:67-72, 2002.

80. Stevens PJ, Lee RJ. Formulation kit for liposomal doxorubicin composed of lyophilized liposomes. Anticancer Res 23:439-442, 2003. 